\title{
Transformer's Condition Assessment Method Based on Combination of Cloud Matter Element and Principal Component Analysis
}

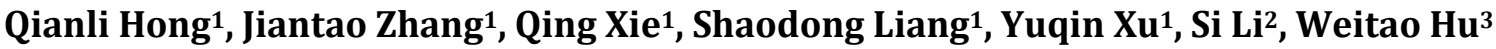 \\ ${ }^{1}$ Department of Electrical Engineering, North China Electric Power University Baoding, Hebei, China \\ ${ }^{2}$ Beijing Electric Power Corporation, Beijing, China \\ ${ }^{3}$ State Grid Hebei Maintenance Branch, Shijiazhuang, China \\ Email:497796355@qq.com
}

How to cite this paper: Hong, Q.L. Zhang, J.T., Xie, Q., Liang, S.D., Xu, Y.Q., Li, S. and Hu, W.T. (2017) Transformer's Condition Assessment Method Based on Combination of Cloud Matter Element and Principal Component Analysis. Energy and Power Engineering, 9, 659-666. https://doi.org/10.4236/epe.2017.94B071

Received: March 9, 2017

Accepted: March 30, 2017

Published: April 6, 2017

\begin{abstract}
With the development of power grid, as one of the key equipment, the transformer's condition assessment method has always receive attention from experts, scholars concern more and more about the method's practicality and reliability. In the traditional condition assessment method, due to the characteristics of the transformer's complex structure, the assessment system is not comprehensive enough, or the assessment system is too complex, the indexes are not easy to quantify, such problems are emerging. The traditional method is complex and the degree of quantification is not enough. Therefore it is necessary to propose a condition assessment method that is easy to carry out the condition assessment work and does not affect the assessment results. In this paper, we propose a method to assess the state of the transformer's complex structure. First, we establish a comprehensive assessment system, then apply the method of principal component analysis to optimize the index system, and then use the theory of cloud-matter-element. Finally the reliability and rationality of the method are verified by an example.
\end{abstract}

\section{Keywords}

Transformer, Assessment Method, Principle Component Analysis, Cloud Model

\section{Introduction}

For a long time, as the important electrical equipment in power system, the transformer's reliable and stable state is meaningful to ensure the safe and healthy operation of the power grid. While its condition assessment work is an 
important prerequisite to transformer's operation. Assess transformer's condition precisely is a basic work for subsequent work like condition based maintenance. Therefore if the condition assessment result is reliable depends on the assessment method.

At present, the research on the condition assessment method of the transformer has made some achievements. Zhang Jingjing and others have adopted the fuzzy analytic hierarchy process to carry out the weighted evaluation of the condition indexes of the transformer on site [1]; Liao Ruijin and others establish the state function of the evaluation index of the insulating oil test and the state function considering the difference of the initial value [2]; Wang Youyuan proposed a comprehensive life evaluation model of the transformer based on the health level diagnosis technology [3]; Zhao Wenqing and others proposed a transformer status assessment model based on Bayesian network [4].

Although the above methods have adopted the advanced method of transformer condition assessment, we can find that most methods are focus on the condition assessment process, they pay less attention to the condition indexes system of assessment process. Meanwhile, some existing assessment system is not comprehensive enough, and some are too complicated, they are all not good for the subsequent condition assessment. As for assessment methods, some indexes which are difficult to quantify also affect the results, therefore it is necessary to propose a more reasonable condition assessment method.

This paper first establish the condition assessment system of transformer, and then introduce the idea of principal component analysis [5] [6] to optimize the original system and build a system with less indexes. Then we use cloud-matterelement theory to assess transformer's condition [7] [8] [9]. The result indicates after using the combination of PCA and cloud model method will not affect the true condition, which proves the feasibility and rationality of the method.

\section{Establishment and Optimization of the Transformer's Condition Assessment System}

As the first step of the transformer's condition assessment process, a perfect condition assessment system need to be built at the beginning. Every parts of the transformer may break down because of its complicated structure, meanwhile, different fault has different physical measurement, therefore, we need to set up a complete system. Meanwhile, a very complete system may be too complicated to do the assessment work, an appropriate method is necessary to simplify the system. Principle component analysis (PCA) is a suitable way to finish the process.

\section{A. Construction of transformer and corresponding faults}

On the basis of transformer's structure we can divide a transformer into 6 parts: tank, winding, iron core, cooling system, tapping switch and bushing. We need to first figure out the corresponding part of fault type before establishing the system. Refer to <summary of technical standard for maintenance of grid equipment $>[10]$ and engineering statistics, we can draw a table about key faults occurred in a transformer as follows Table 1. 
Table 1. Key faults occurred in a transformer.

\begin{tabular}{cc}
\hline construction & key failure \\
\hline Transformer tank & Oil leakage, Partial discharge, Deformation \\
Transformer winding & Insulation drops, Abnormal resistance, Discharge failure, Short circuit fault, Winding deformation, Overload \\
Transformer core & Multi-point grounding, Insulation drops, Core deformation, Over excitation, Oil blockage, Magnetic flux leakage \\
Oil leakage, Insulation damp, Porcelain sets flashover, Ageing, Partial discharge, \\
Mransformer bushing & Magnetic flux leakage, Insulation breakdown \\
Transformer & Oil leakage, Oil flow circuit unreasonable, Heat pipe clogged, Cooler outage, Fan exception \\
cooling system & Abnormal action, Partial discharge, Tap connection error, Oil leakage, Insulation drops, Mechanical damage \\
\hline
\end{tabular}

\section{B. Establishment of condition assessment system}

The establishment of assessment system needs to seek fault's corresponding physical measurement which could conduct as indexes of assessment system. However, because two different components may have same measurement, such as cooling system and tank all have temperature measurement, therefore we need to filter the main measurement before the assessment. According specialist's suggestion and content of the summary, we can select the most important measurement to form the system, the initial system is as follows Figure 1.

C. Optimization for assessment system based on principle component analysis

Principle component method can apply in many aspects of multivariate statistical analysis. Its basic theory is to use ideology of decreasing dimension. We can build a new index system by using a certain of algorithm on the basis of multi-parameter and multi-sample data array. Though the quantity of indexes in new system decreased, they can reflex initial system's information more intensively. The new index parameters are called principle component. The key steps are as follows:

1) Standardize $p$ indexes value in $n$ samples to obtain matrix $Z$.

2) Build correlation coefficient matrix $R=Z Z Z^{T} /(n-1)$, calculate $p$ eigenvalues: $\lambda_{1} \geq \lambda_{2} \geq \lambda_{3} \geq \ldots \geq \lambda_{\mathrm{p}} \geq 0$, then calculate their corresponding feature vector: $\mathrm{e}_{\mathrm{j}}=\left(\mathrm{l}_{1 \mathrm{j}}, \mathrm{l}_{2 \mathrm{j}}, \ldots, \mathrm{l}_{\mathrm{pj}}\right)$.

3) Calculate variance contribution rate: $\alpha_{\mathrm{j}}=\lambda_{\mathrm{j}} / \sum \lambda_{\mathrm{j}}$, then sort rate and make sure that when first $\mathrm{m}$ indexes' accumulating rate more than 0.85 , we can regard these $m$ principle components can reflect $\mathrm{p}$ indexes.

4) Calculate $n$ sample's principle component: $M_{i, j}=Z_{i j} \times\left[e_{1}, e_{2}, \ldots, e_{p}\right]$.

We can discover that there are correlation between new assessment indexes. The initial system could be optimized into a new compact system to asses on the base of PCA method.

\section{Transformer Condition Assessment Method Based on Cloud Model}

A. Determining the weight of index based on the combination of PCA and analytic hierarchy process

On the one hand, in the process of PCA mentioned above, accumulating rate can be regarded as principle components' important level to transformer's over- 


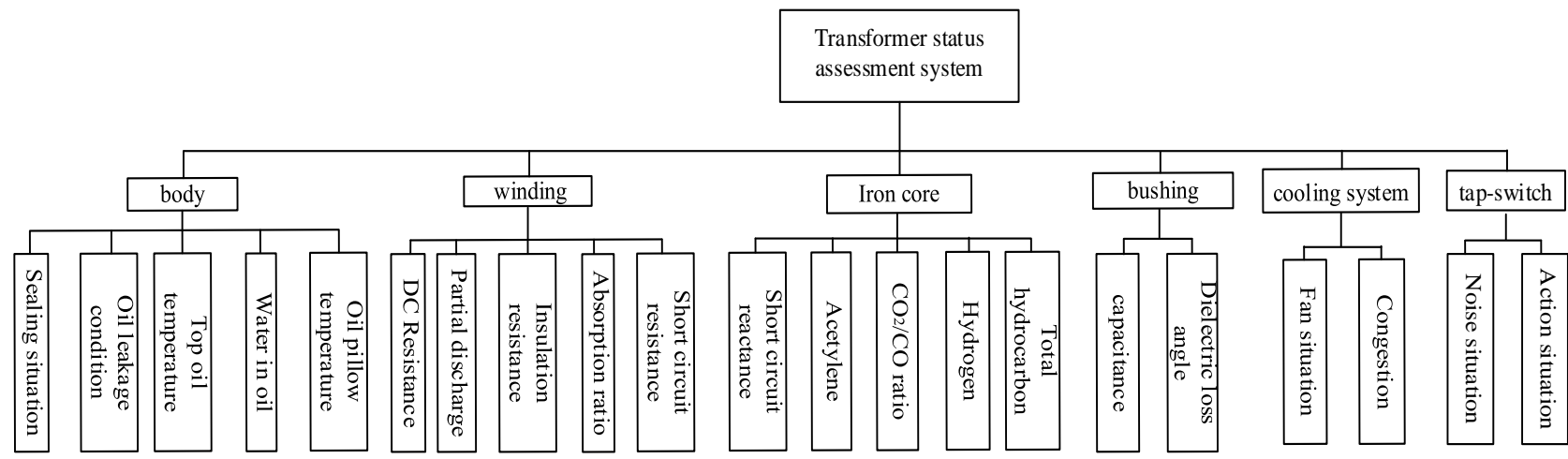

Figure 1. Transformer's condition assessment system.

all condition, meanwhile, the component's feature sector value can be seen as indexes' weight, because in the steps of PCA, we choose the absolute value greater than 0.3 as the new index among feature sector, the absolute value could also be seen as indexes' weight. On the other hand, the rate is calculated by samples' value, therefore the rate is objective which could represent objective weight. We can use analytic hierarchy process to calculate subjective weight based on experts' opinion on site. Finally we can use comprehensive weight method to calculate integrated weight, the main steps are as follows Figure 2.

\section{B. Transformer's condition assessment based on cloud model}

The cloud matter-element model is an uncertain transformation model expressed by Li Deyi. The model is used to describe the qualitative concept and its quantitative representation. The model consists of three eigenvalues: entropy and super entropy. There are many indexes which are not easy to quantify directly except other quantifiable indexes in assessment system, such as tank's oil leakage situation, mechanical vibration situation and so on. As for these indexes, we can use cloud model to simulate quantization. The main steps of cloudmodel assessment method are as follows:

1) Establishment of indexes' standard cloud

According to possible consequences of assessment, firstly we can divide the consequences into four class: normal, noticeable, abnormal, serious. Then we can define the interval upper limit and lower limit as $c_{\max }$ and $c_{\min }$ before we calculate three eigenvalues. Two eigenvalues' formula are as follows.

$$
\begin{aligned}
& E_{x}=\left(c_{\text {min }}+c_{\text {max }}\right) / 2 \\
& E_{n}=\left(c_{\text {max }}-c_{\text {min }}\right) / 6
\end{aligned}
$$

2) Calculate the indexes' correlation of cloud model

We can use this formula to calculate the correlation:

$$
\mathrm{y}=\exp \frac{-\left(x-E_{x}\right)^{2}}{2\left(E_{n}\right)^{2}}
$$

$Y$ represents $x^{\prime}$ correlation value. We can calculate every class' correlation of assessment index:

$$
k_{j}(p)=\sum_{i=1}^{m} w_{i} y_{i}
$$




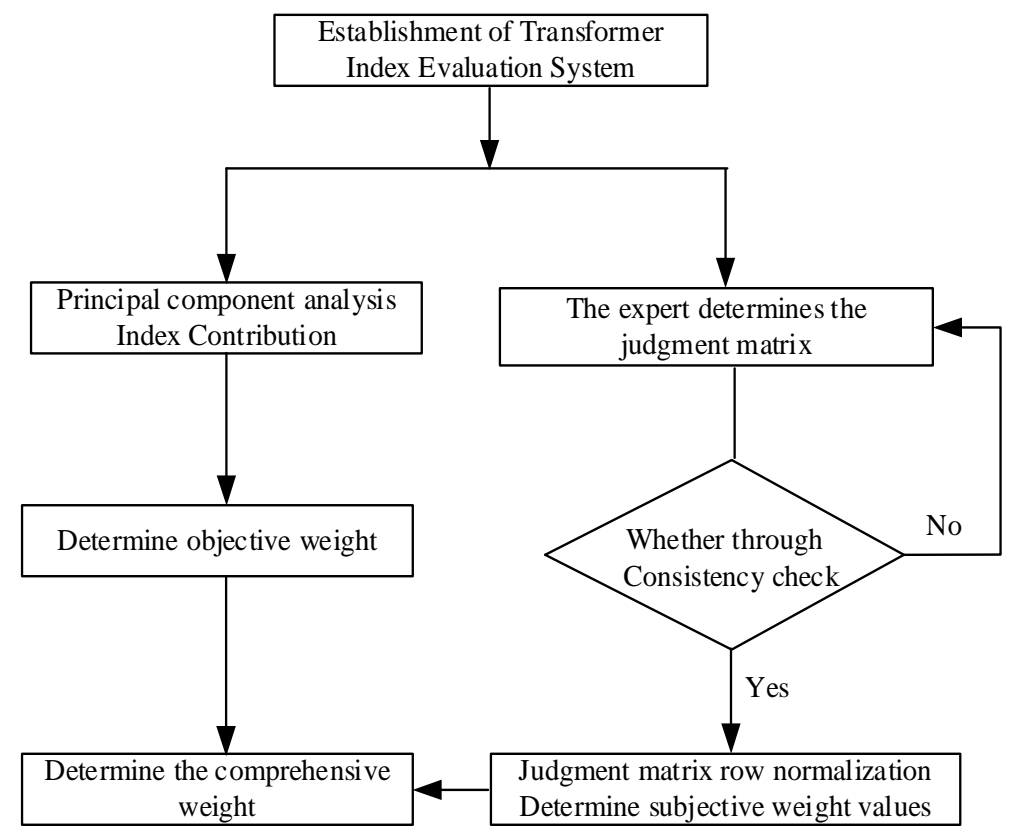

Figure 2. Flow chart of weight calculating.

$w_{i}$ is comprehensive weight calculated from last section, $y_{i}$ is correlation of every class. Finally, we can determine the condition class by the principle of maximum membership.

\section{Case study}

This paper choose a power supply bureau's 5 transformers before repair to make case study. Their original data are as Table 6, there are some indexes which are not easy to quantify among them such as "sealing condition". According to 4 classes as mentioned before, we can rate them by using " 1 " " 2 " " 3 " " 4 " as responding 4 classes.

We can use PCA to handle these data and find there are 4 eigenvalues greater than 0: $\lambda_{1}=2.6397, \lambda_{2}=4.2956, \lambda_{3}=4.9412, \lambda_{4}=9.1235$. After sorting them we can find that $\lambda_{4}, \lambda_{3}, \lambda_{2}$ these 3 eigenvalues' accumulating rate are greater than $85 \%$, therefore they are the 3 principle components. Next we choose indexes whose absolute value is greater than 0.3 from every component's eigenvector. The first principle component consist of 4 indexes: tank's oil temperature, winding's short circuit resistance, iron core's total hydrocarbon content, iron core's acetylene content; the second component's indexes: tank's oil pillow sealing situation, iron core's hydrogen content, tap-switch's action situation, bushing's capacitance; the third principle's indexes are winding's absorption ratio, winding's partial discharge, iron core's co2/co ratio and cooling system's fan situation. We can assess the condition by using these 3 principles. We choose $1 \#$ transformer's state value to assess condition. The standard summary could tell us the value range of every index. Every index's value range is divided into 4 classes as mentioned. The cloud model is as follow Table 2.

According to the assess process, we choose new indexes' variance contribution rate as subjective weight. Their values are as Table 3 after using AHP. 
Table 2. Cloud model of $1 \#$ transformer.

\begin{tabular}{|c|c|c|c|c|c|}
\hline & Index & Normal & Noticeable & Abnormal & Serious \\
\hline \multirow{4}{*}{$\begin{array}{c}\text { NO.1 } \\
\text { Principle } \\
\text { component }\end{array}$} & Tank's oil temperature & $66,0.6667,0.5$ & $70,0.6667,0.5$ & $74,0.6667,0.5$ & $78,0.6667,0.5$ \\
\hline & Winding's short circuit resistance & $0.005,0.00167,0.5$ & $0.015,0.00167,0.5$ & $0.025,0.00167,0.5$ & $0.035,0.00167,0.5$ \\
\hline & Iron core's total hydrocarbon content & $145,1.6667,0.5$ & $155,1.6667,0.5$ & $165,1.6667,0.5$ & $175,1.6667,0.5$ \\
\hline & Iron core's acetylene content & $0.75,0.0833,0.5$ & $1.25,0.0833,0.5$ & $1.75,0.0833,0.5$ & $2.25,0.0833,0.5$ \\
\hline \multirow{4}{*}{$\begin{array}{c}\text { NO.2 } \\
\text { Principle } \\
\text { component }\end{array}$} & Oil pillow's sealing situation & $92.5,2.5,0.5$ & $77.5,2.5,0.5$ & $62.5,2.5,0.5$ & $47.5,2.5,0.5$ \\
\hline & Iron core's hydrogen content & $145,1.6667,0.5$ & $155,1.6667,0.5$ & $165,1.6667,0.5$ & $175,1.6667,0.5$ \\
\hline & Tap-switch's action situation & $92.5,2.5,0.5$ & $77.5,2.5,0.5$ & $62.5,2.5,0.5$ & $47.5,2.5,0.5$ \\
\hline & Bushing's capacitance & $0.005,0.00167,0.5$ & $0.02,0.00333,0.5$ & $0.04,0.00333,0.5$ & $0.06,0.00333,0.5$ \\
\hline \multirow{4}{*}{$\begin{array}{c}\text { NO.3 } \\
\text { Principle } \\
\text { component }\end{array}$} & Winding's absorption ratio & $1.35,0.01667,0.5$ & $1.25,0.01667,0.5$ & $1.15,0.01667,0.5$ & $1.05,0.01667,0.5$ \\
\hline & Winding's partial discharge & $0.75,0.0167,0.5$ & $0.85,0.0167,0.5$ & $0.95,0.0167,0.5$ & $1.05,0.0167,0.5$ \\
\hline & Iron core's co $2 /$ co ratio & $5,1.667,0.5$ & $20,3.333,0.5$ & $35,3.333,0.5$ & $45,3.333,0.5$ \\
\hline & Cooling system's fan situation & $92.5,2.5,0.5$ & $77.5,2.5,0.5$ & $62.5,2.5,0.5$ & $47.5,2.5,0.5$ \\
\hline
\end{tabular}

Table 3. Subjective weight.

\begin{tabular}{cccc}
\hline & NO.1 PC & NO.2 PC & NO.3 PC \\
\hline Index 1 & 0.32 & 0.145 & 0.263 \\
Index 2 & 0.276 & 0.283 & 0.347 \\
Index 3 & 0.216 & 0.264 & 0.124 \\
Index 4 & 0.188 & 0.308 & 0.266 \\
\hline
\end{tabular}

The comprehensive weight is as follows Table 4.

Then according to cloud-matter-element theory to calculate indexes' correlation value as follows Table 5 .

According to maximum membership principle we can find that the condition of the $1 \#$ transformer's condition is "noticeable" which conforms to the actual situation. Therefore it proves that after optimizing the assessment system, using cloud-model method could keep the condition's accuracy and simplify the whole assess process.

\section{Conclusions}

1) The establishment of a perfect transformer condition assessment system is an important step of assessment process. We can optimize the system by using PCA which could not only receive reliable assess conclusion, but also decrease condition measurement. The method has its practical significance. (Table 6)

2) Through the condition assessment method based on cloud-model, we could quantize all the indexes in assessment system according practical situation, plus, the objective weight calculated in PCA process avoids the abuse of only us- 
Table 4. Comprehensive weight.

\begin{tabular}{rccc}
\hline & NO.1 PC & NO.2 PC & NO.3 PC \\
\hline Index 1 & 0.083 & 0.055 & 0.100 \\
Index 2 & 0.081 & 0.082 & 0.113 \\
Index 3 & 0.065 & 0.084 & 0.081 \\
Index 4 & 0.065 & 0.088 & 0.106 \\
\hline
\end{tabular}

Table 5. Correlation value of 4 ranks.

\begin{tabular}{cc}
\hline Rank & Correlation value \\
\hline Normal & 0.112 \\
Noticeable & 0.204 \\
Abnormal & 0.056 \\
serious & 0.011 \\
\hline
\end{tabular}

Table 6. Transformers' original data.

\begin{tabular}{|c|c|c|c|c|c|c|c|c|c|c|c|c|c|}
\hline PART & INDEX & $1 \#$ & $2 \#$ & $3 \#$ & $4 \#$ & $5 \#$ & PART & INDEX & $1 \#$ & $2 \#$ & $3 \#$ & $4 \#$ & $5 \#$ \\
\hline \multirow{6}{*}{ BODY } & Sealing condition & 2 & 4 & 3 & 2 & 4 & \multirow{5}{*}{ IRON CORE } & Ground current (A) & 0.14 & 0.36 & 0.07 & 0.28 & 0.19 \\
\hline & $\begin{array}{c}\text { Oil pillow } \\
\text { temperature }\left({ }^{\circ} \mathrm{C}\right)\end{array}$ & 69 & 78 & 66 & 74 & 83 & & Total hydrocarbon $(\mu \mathrm{L} / \mathrm{L})$ & 158 & 178 & 144 & 158 & 163 \\
\hline & $\begin{array}{c}\text { Top oil } \\
\text { temperature }\left({ }^{\circ} \mathrm{C}\right)\end{array}$ & 52 & 59 & 50 & 59 & 61 & & Acetylene $(\mu \mathrm{L} / \mathrm{L})$ & 1.2 & 2.3 & 0.8 & 1.5 & 2.1 \\
\hline & \multirow{2}{*}{ Oil leakage condition } & \multirow{2}{*}{3} & \multirow{2}{*}{3} & \multirow{2}{*}{4} & \multirow{2}{*}{1} & \multirow{2}{*}{4} & & $\mathrm{CO}_{2} / \mathrm{CO}$ ratio & 30 & 38 & 46 & 34 & 35 \\
\hline & & & & & & & & Hydrogen $(\mu \mathrm{L} / \mathrm{L})$ & 157 & 169 & 148 & 155 & 145 \\
\hline & Water in oil (ppm) & 5 & 9 & 3 & 4 & 6 & \multirow{3}{*}{ SWITCH } & Action situation & 2 & 3 & 4 & 3 & 4 \\
\hline \multirow{6}{*}{ WINDING } & Short circuit & 1 & 20 & 1 & 5 & 42 & & Noise & 4 & 3 & 3 & 1 & 2 \\
\hline & resistance (\%) & 1.4 & 3.0 & 1.1 & 2.5 & 4.5 & & Capacitance (\%) & 0.8 & 1.4 & 2 & 0.9 & 1.9 \\
\hline & $\begin{array}{c}\text { Insulation } \\
\text { resistance }(\mathrm{M} \Omega)\end{array}$ & 18 & 10 & 21 & 13 & 19 & \multirow[t]{2}{*}{ BUSHING } & \multirow{2}{*}{$\begin{array}{c}\text { Dialectric } \\
\text { loss angle (\%) }\end{array}$} & \multirow[t]{2}{*}{2} & \multirow[t]{2}{*}{4.3} & \multirow[t]{2}{*}{1.2} & \multirow[t]{2}{*}{1.5} & \multirow[t]{2}{*}{3.8} \\
\hline & Absorption ratio & 1.2 & 1.09 & 1.34 & 1.45 & 1.26 & & & & & & & \\
\hline & Partial discharge (\%) & 76 & 98 & 89 & 65 & 9 & \multirow{2}{*}{$\begin{array}{l}\text { COOLING } \\
\text { SYSTEM }\end{array}$} & Congestion & 2 & 3 & 4 & 2 & 2 \\
\hline & DC resistance (\%) & 1.26 & 1.08 & 0.82 & 0.94 & 1.35 & & Fan situation & 3 & 4 & 3 & 2 & 1 \\
\hline
\end{tabular}

ing AHP to calculate weight. The method also makes the process of calculating weight more reliable and easy. The combination of PCA and cloud-model makes the whole assess process more reasonable and effective.

\section{References}

[1] Zhang, J.J., Xu, X.L., Ding, M., et al. (2017) A Condition Assessment Method of Power Transformers Based on Fuzzy Analytic Hierarchy Process. Power System Protection and Control, 3, 1-7.

[2] Liao, R.J., Huang, F.L., Yang, L.J., et al. (2010) Multi - information Fusion Model of Power Transformer State Evaluation. High Voltage Technology, 6, 1455-1460. 
[3] Wang, Y.Y. and Chen, B.J. (2014) Transformer Health Status and Comprehensive Life Evaluation Model Based on Analytic Hierarchy Process. Power grid technology, 10, 2845-2850.

[4] Zhao, W.Q., Zhu, Y.L., Jiang, B., et al. (2008) Condition Assessment for Power Transformers by Bayes Networks. High Voltage Technology, 5, 1032-1039.

[5] Qi, M.F., Fu, Z.G., Jing, Y., et al. (2013) A Comprehensive Evaluation Method of Power Plant Units Based on Information Entropy and Principal Component Analysis. Proceeding of CSEE, 2, 58-64+12.

[6] Jiang, H.Y., Wang, W.X. (2004) Application of Principal Component Analysis in Synthetic Appraisal for Multi-objects Decision-making. Journal of Wuhan University of Technology (Transportation Science \& Engineering), 3, 467-470.

[7] Zhu, Y.L., Gong, Z., Wu, Z.L., et al. (2010) The Application of Normal Cloud Model In Condition Assessment in Power Transformers. Journal of North China Electric Power University (Natural Science Edition), 5, 27-31.

[8] Wang, G.Y., Li, D.Y., Yao, Y.Y., et al. (2013) Cloud Model and Particle Calculation. Science Press, Beijing.

[9] Fei, X., Li, F., Hao, Y.S., et al. (2012) A Synthetic Power Quality Evaluation Model Based on Cloud Matter Element Analysis Theory. Dianli Xitong Baohu $Y u$ Kongzhi/Power System Protection \& Control, 40, 6-10.

[10] Shuai, J.Q., Zhang, L.Y., Zhang, Q., et al. (2012) Power Equipment Equipment State Maintenance Technical Standards Compilation. China Electric Power Press, Beijing.

Submit or recommend next manuscript to SCIRP and we will provide best service for you:

Accepting pre-submission inquiries through Email, Facebook, LinkedIn, Twitter, etc. A wide selection of journals (inclusive of 9 subjects, more than 200 journals)

Providing 24-hour high-quality service

User-friendly online submission system

Fair and swift peer-review system

Efficient typesetting and proofreading procedure

Display of the result of downloads and visits, as well as the number of cited articles

Maximum dissemination of your research work

Submit your manuscript at: http://papersubmission.scirp.org/

Or contact epe@scirp.org 